\title{
UN EPISODIO DE JAVIER MARÍAS LA ESPADA DE TUPRA EN TU ROSTRO MAÑANA
}

\author{
Héctor Brioso Santos \& Máximo Brioso Sánchez \\ Universidad de Alcalá de Henares \& Universidad de Sevilla
}

\begin{abstract}
Resumen: Respecto a un episodio de Tu rostro mañana de Javier Marías se ha sugerido una influencia cervantina. Aquí se discute en profundidad esta propuesta: el origen del episodio se explica en el propio texto de Marías. Y se revisan a la vez otros aspectos literarios del autor y sobre todo de esta obra relacionados con el tema debatido.

Palabras clave: Novela española contemporánea, Marías, Tu rostro mañana

Abstract: Concerning an episode of Javier Marias' Tu rostro mañana an influence of Cervantes has been suggested. Here we discuss this proposal in depth: the origin of the episode is explained in Marias's own text. And, at the same time, we review other literary aspects of the author, and especially of that work, related to the subject under discussion.
\end{abstract}

Keywords: Contemporary Spanish novel, Marías, Tu rostro mañana

En las páginas que siguen se va a discutir la opinión de un estudioso acerca de un posible origen literario (en particular, una influencia del Quijote cervantino) de un momento concreto en un largo episodio de Tu rostro mañana. Más tarde debatiremos en detalle la que creemos falta de rigor de esta propuesta y ofreceremos nuestra propia solución. Pero previamente conviene que situemos el episodio en discordia en relación con ciertas tendencias apreciables en la obra de Javier Marías, tres en concreto, y que, como se verá, pueden contribuir a situar y clarificar los términos de la discusión.

En la ficción de Javier Marías se practica por lo general, como propensión fácilmente detectable, un realismo que arranca de la vida cotidiana. Pero, como excepciones no infrecuentes dentro de esta tendencia y que podrían catalogarse, no faltan en su producción elementos calificables en sentido amplio de improbables, lo que para nosotros aquí significa, fuera de otras complicaciones que en buena parte se derivan del concepto aristotélico de la inverosimilitud, lo que se considera no imposible pero es poco o muy poco verosímil; en suma, lo que parece chocar con la lógica o la simple experiencia. Se debe separar, pues, 
adecuada y tajantemente esa improbabilidad de las desviaciones de la realidad que son típicas, por ejemplo, del llamado "realismo mágico" y no digamos de una literatura como la gótica o, por supuesto, la ciencia ficción. En Marías parece existir una inclinación a limitar estas otras posibilidades a sus cuentos, y así lo ha señalado Irene Andres-Suárez cuando concluye que esta propensión, presente en sus relatos cortos, a mundo onírico y sobre todo a literatura fantástica y de terror está, en cambio, ausente en sus novelas $(2005)^{1}$. E igualmente queda así comprobado en otros estudios sobre esos rasgos no realistas de sus cuentos ${ }^{2}$. En resumen, no se trata de una diferencia de grado o de un simple matiz, sino de dos tendencias perfectamente separables. La una escapa, más o menos eventualmente, del nivel de la realidad; la otra, la de la mera improbabilidad, nos ofrece un aspecto posible de lo real, pero que la experiencia de los lectores puede fácilmente poner en cuarentena.

No se plantea, por tanto, en este caso la distinción que suele establecerse respecto a la llamada literatura fantástica, la del ámbito de lo posible frente al de lo imposible. Así que no estamos ante una situación que nos lleve a expresarnos como Tzvetan Todorov en un libro ya clásico sobre el tema: "Dans un monde qui est bien le nôtre, celui que nous connaissons, sans diables, sylphides, ni vampires, se produit un événement qui ne peut s'expliquer par les lois de ce même monde familier" (1970: 29).

Es, pues, la simple improbabilidad (o inverosimilitud) la que sobre todo nos importa aquí. Y por no ser nosotros los calificadores, recurrimos, como ejemplo, a una página del crítico Ignacio Echevarría en la que utiliza el adjetivo "inverosímil" para referirse a un pasaje de Mañana en la batalla piensa en mî. Y, con este criterio, cabría calificar también de improbables otros momentos de sus novelas. Así, por ejemplo, es muy poco imaginable, aunque por supuesto no imposible, que, en Corazón tan blanco, quienes ocupan una habitación de hotel escuchen con bastante nitidez lo que se dice en otra: podríamos hablar en este caso de una inverosimilitud, si se quiere, menor o leve. Pero cabe señalar también una improbabilidad grave en casos en los que, si esos hechos se dieran en la realidad y, por tanto, sin ser imposibles o portentosos, causarían una gran extrañeza, y esto simplemente porque se nos antojaría bastante absurdo que se

${ }^{1}$ Por ejemplo, el relato juvenil titulado "La vida y la muerte de Marcelino Iturriaga" (que puede leerse en el volumen Mientras ellas duermen, 2007: 19-23) y que responde a un evidente "realismo mágico". A Elide Pittarello, en el prólogo de esta edición, le llama la atención que este cuento "revele una vocación tan temprana por el género fantástico" (10). Y el propio autor, en su "Nota previa" a esta misma colección, señala su semejanza con "Cuando fui mortal", ya de 1993 (15). Lo mismo cabría decir de algunos otros, con inclusión de "Gualta", de 1986, en el que unos hermanos aparecen como disparatadamente "gemelos".

2 Véanse David Roas (2005), que escribe igualmente que se trata de "un elemento ausente en sus novelas pero ampliamente desarrollado en su narrativa breve” (218), y Rebeca Martín (2005: 231-241).

3 “...Un episodio transversal -fatigoso por inverosímil- en que el narrador refiere retrospectivamente un lance con una prostituta...”(2005: 147 s.). 
dieran en la práctica. Esto lo vemos con suma claridad en la misma Mañana en la batalla piensa en mí, en la escena inicial en la vivienda de Marta Téllez y en la enfatizada particularidad de que el teléfono tiene contestador. Y se trata, recordemos, de un piso en el que convive un matrimonio, siendo irrelevante aquí que el esposo esté ausente mientras tienen lugar los sucesos narrados. Pues lo gravemente inverosímil es que ese contestador compartido recoja llamadas comprometedoras para uno y otro cónyuge, lo que exhibe los secretos de cada uno ante el otro. Y podríamos también añadir que tampoco es muy verosímil que la cita erótica que es el centro del episodio ocurra en una situación en la que Marta Téllez está acompañada de su hijo, aunque éste sea un niño pequeño, pero perfectamente capaz de recordar, como se demostrará después, la figura del acompañante de Marta en esa cita frustradamente adúltera. De hecho, se alude en el texto repetidamente a los inconvenientes de la presencia en la escena de ese tercer actor, el hijo de Marta. Como si la referencia concreta a tales inconvenientes redujera la incomodidad de esa presencia. Y, como se verá después respecto al episodio que discutiremos, también la de éste estará acompañada de supuestas justificaciones del hecho que debe provocar casi forzosamente la sorpresa del lector (por no hablar de los testigos de lo narrado), sean cuales sean sus criterios sobre lo que es improbable. Y esto ocurre en una novela (Tu rostro mañana) en la que no faltan otras inverosimilitudes: así, una notable y de gran peso en el relato es la muy relevante existencia y el funcionamiento de la agencia en la que trabajan un tal Tupra y otros personajes (dotados de un "don especial", "un raro don", "un don hoy rarísimo, cada vez más infrecuente” y que se nos explica por boca de Peter Wheeler $(266)^{4}$, la cual agencia tiene no sólo una estrambótica función sino la cualidad no fácilmente creíble de servir a una diversidad de clientes tanto oficiales como privados 5 . Y no se trata, aclaremos aunque sea innecesariamente para quienes hayan leído esta extensa novela, de una simple agencia de detectives.

El segundo aspecto que tiene que ver con nuestro tema es el del culto, no raras veces fetichista, que los personajes de Marías rinden al capítulo de los objetos y que ha sido estudiado, si bien no en detalle, por Elide Pittarello ${ }^{6}$. La autora analiza datos como la presencia de las ilustraciones y otros, pero lo que nos importa es el hecho que señala de la vinculación de ciertos objetos con los personajes en el sentido de que aquellos son utilizados narrativamente como

${ }^{4}$ A partir de ahora y siempre que aludamos a esta novela la paginación corresponderá, para mayor comodidad, a la edición en un solo volumen (2009) y no a la primera en tres, como ha sido frecuente. Hoy creemos que está fuera de lugar citar por una edición de tan incómodo manejo.

${ }^{5}$ En pp. 791 ss. se nos ofrece una pretendida justificación de esto último.

6 2005: 17-48. El propio autor en algunos artículos periodísticos ha subrayado esta faceta de su personalidad: una vez más narrador y autor muestran fuertes coincidencias. No es éste, sin embargo, el lugar para referirnos a la concepción de la novela que está detrás de éste y de otros aspectos narrativos y cuya definición ha sido intentada por diversos autores, entre ellos Alexis Grohmann en una muy reciente monografía (2011). 
partes muy relevantes de las circunstancias de los individuos: así, los objetos personales ya sea de vivos como de difuntos, o, en el uso que Pittarello considera "heterodoxo", mucho más expresivo y que pasa a un primer plano sobre todo con la publicación de Todas las almas. En nuestro caso, no hay duda de que la espada como objeto insistente y de la que deberemos hablar ha de interpretarse como una parte esencial de la conducta de un personaje concreto, Tupra, y como tal no sólo ocupa un lugar de extraordinario peso en relación con esa figura, sino que condiciona una porción importante de la narración.

Pero el uso de una espada modernamente y en una situación como la que se describe en el aludido episodio de Tu rostro mañana responde, al menos en una primera impresión, además de a algún nivel de inverosimilitud y, si se quiere, de ese culto al objeto en relación con los personajes, a un tercer elemento que igualmente debe tenerse en cuenta. $Y$ es que, como se ha hecho notar más de una vez entre sus críticos y estudiosos, en los relatos de Marías también se observa cierta propensión a recurrir a lo que en sentido amplio cabría conceptuar como anacronismos. En el episodio en cuestión, que es parte del escenario londinense del relato, se nos cuenta cómo el citado personaje Tupra acomete con una espada en los servicios "de los tullidos" de una discoteca a un tal De la Garza ${ }^{7}$. Así que no es, por supuesto, la mera mención, incluso la aparición, de esa espada lo que puede sorprendernos y permitirnos hablar de inverosimilitud y menos aun de anacronismo, sino las particulares circunstancias en las que se exhibe el arma. Por citar algún caso igualmente vinculado al equipamiento militar antiguo, aunque esta vez se trate de un nivel puramente poético, podemos recordar como una curiosa muestra que en Mañana en la batalla piensa en mi de la voz del personaje Deán se dice que "es grave, oxidada y ronca, como si saliera de un yelmo". Y no es infrecuente que en los textos de Marías se aluda, por ejemplo, a lanzas, lo que ocurrió ya con el título de un cuento ("Sangre de lanza") y alcanza hasta los títulos parciales de Tu rostro mañana ${ }^{10}$. También es sabido y se ha señalado, aunque usualmente sin calificarlo de particular anacronismo sino de mero rasgo de estilo, que un personaje como el mencionado Deán entre otros y, por supuesto, como suele hacer habitualmente el narrador (de esa novela y de otras: Cora Requena Hidalgo: 2003), construya en bastantes

7 Dada su extensión y su entrelazamiento con otros temas y digresiones, no es fácil acotarlo en el texto. Baste decir por ahora que se inicia en la parte titulada "Baile" y, en principio, termina en la p. 709, cuando varios de los actores del episodio salen de la discoteca (dentro ya de la parte "Sueño"), si bien después también habremos de referirnos a otros momentos relacionados estrechamente con él.

${ }^{8}$ P. 186 de la edición de 1996.

${ }^{9}$ Integrado en el volumen Cuando fui mortal (1996).

10 Por supuesto, la cita de una espada tampoco falta en otros textos del autor: Por ejemplo, en Corazón tan blanco se lee esta frase (2006: 195): "Su mano sobre mi hombro fue casi el golpe de la espada plana que armaba caballero a quien no lo era”, con la prueba, una vez más, del gusto de Marías por lo antiguo. 
ocasiones su pensamiento con giros tomados de pasajes literarios, en particular de Shakespeare. Y, si volvemos al tema de las armas, incluidas las anticuadas, no podemos olvidar en esta misma novela de la que nos ocupamos el episodio madrileño en el que tiene tanta importancia la afición del padre de Deza a coleccionarlas (1167 ss.). Y que en ella el propio narrador, como veremos, aluda al carácter anacrónico del acto central del episodio que examinamos. De modo que, con estos y otros datos que podrían aducirse, no cuesta nada dictaminar que Marías sigue en la escritura de esta obra esa doble tendencia al lucimiento de los objetos, a la insistencia en ellos, y a la vez al anacronismo, que parece estar ciertamente en alguna clase de relación con sus frecuentes muestras, en todo tipo de escritos, de apego al pasado en detrimento de un aprecio por el presente. Al igual que, ya ciñéndonos al episodio que debatimos, se suma el otro ingrediente invocado, el de la inverosimilitud. Y, sobre esta base, en principio no nos costaría demasiado establecer un honroso parangón, en particular, con el amor al anacronismo también practicado por don Quijote, tal como subrayara ya hace años José Antonio Maravall en su caracterización del hidalgo manchego $(1976)^{11}$. Pero el tener en cuenta en el estudio de las obras de Marías, no sólo de ésta, ese hecho de amplio horizonte no debe llegar al extremo de hacernos renunciar a otras motivaciones en el análisis de los problemas planteados por ese y otros relatos. Y el no percatarse de la necesidad de esta precaución, por más que encandile esa mencionada propensión arcaizante, puede llevar fácilmente, como veremos, al error.

En el caso de Tu rostro mañana el anacronismo representado por ese apego a hablar de armas y, en buena parte de los casos, de armas obsoletas, también parece acercarnos al mundo quijotesco y, a través de él, a un género literario que a lo largo del siglo XVI envejeció fatalmente con su culto a un pasado idealizado: el caballeresco. Pues en este género, como ha escrito Javier Guijarro Ceballos, "no podemos prescindir del estudio de las armas... Su participación visual en la imagen transmitida del caballero andante y en las descripciones del combate, así como su función en la creación literaria de algunas aventuras caballerescas, es esencial para la poética 'destos caballerescos libros'”(2007: 187). Y, por supuesto, como igualmente muestra el análisis de Guijarro Ceballos, lo mismo ocurre en la parodia quijotesca. Pero esto, en el tema que nos ocupa y como veremos, insistimos en que no debe inducirnos a sacar unas conclusiones precipitadas.

11 Toda esta monografía está en esencia dedicada al mismo tema bajo distintas perspectivas. Un resumen puede ser este pasaje (169): "Hemos visto... que su protagonista proclama, bajo una doble faz, cuál es su misión. De un lado, restaurar la orden de caballería; de otro, hacer renacer los siglos de oro... Como es normal en tantos programas de reforma, la novedad consiste en un restablecimiento: volver a traer al presente la imagen de una sociedad perfecta entrevista apenas en una lejanía imprecisa...”. Y todo el Quijote no es sino un programa de demostración del fracaso de esa utopía de restauración. Nada de esto se da, sin embargo, en Tu rostro mañana ni, más en concreto, en el personaje de Tupra. 
Es innegable, desde luego, que el episodio de la espada de Tu rostro mañana ofrece, en principio, el interés de este recurso al anacronismo, con su centro en el uso de un arma sorprendente en una situación inapropiada, combinado aquí, como decimos, con una fuerte dosis de inverosimilitud y que, si nos limitamos al mismo tema del armamento, se repite con muy alta frecuencia en esta novela: así, "espada" y "lanza" sobre todo son términos esparcidos a lo largo de ella y en muy diversos contextos. Y no se trata sólo de las citas o alusiones literarias, como la de "lanza y fiebre" (150) o "lanza" (447) ${ }^{12}$, sino de otros muy diversos empleos insertos en el relato y tanto fuera como en el interior por supuesto del episodio que examinamos. Así, sin querer agotar el catálogo de menciones y excluyendo provisionalmente las referidas sólo a la espada y con especial interés para nosotros, se citan seguidas flecha, espada y lanza en una digresión en el curso del propio episodio (531). Pero ya antes de él, "lanza", por ejemplo, aparece en una serie de momentos $(119,143,150,161$, etc.), y espadas y lanzas como objetos decorativos y como armas (310). Leemos la comparación de un paraguas apoyado en el hombro con "un fusil o una lanza cuando se desfila"(271) y (en 427) se da un símil equiparable: un paraguas como un sable, tal como se encuentra un yelmo metafórico en 323 y, de nuevo y junto con el escudo, un yelmo igualmente imaginario en 703, un sable heráldico en 324, unas metafóricas "lanzas de agua" y "lanzas interminables", para referirse reiteradamente a la lluvia (424, cf. de nuevo 811, 844 y 1187), una lanza también "interminable" y figurada para la pena de ausencia en 961, "la bayoneta y la lanza" como armas (451). Igualmente se lee un párrafo dedicado a escudo y yelmo en 703 .

Pero es sobre todo a raíz del episodio de la sala de fiestas cuando a la espada se le concede, aparte de su propio uso, una extraordinaria importancia en el relato, de modo que, si previamente es más rara su mención ${ }^{13}$, después se convierte en un objeto recurrente, asociado o no con la figura de Tupra, con una tan alta densidad que no puede sino ser llamativa y, nos atrevemos a decir, muy significativa. Incluso todavía dentro del episodio, pero sin relación directa con lo que acontece en él, se mencionan digresivamente, según vimos, una espada y otras armas (531), tal como, en las pp. 543 y 546, se vuelve a mencionar una espada con un uso metafórico y dentro de un largo pasaje en el que han cambiado el escenario y los personajes, o como en 627 s. la espada es el centro de una digresión. Una nueva espada, ésta imaginaria, aparece en la referencia al oscuro personaje Manoia y su posible venganza contra el mismo narrador: “...Habría desenvainado su espada contra mí, si acaso llevaba también él una oculta, quién sabía...” (768), con clara alusión al episodio que nos interesa. Luego se la cita varias veces en p. 1075 en la descripción de un cuadro del Museo del Prado,

12 Las menciones que responden a esta categoría en concreto están recogidas en Antonio Iriarte (2009: 303-366).

${ }^{13}$ Cf. concretamente el término "sablazo", pero que anticipa la acción de Tupra en 503. 
igual que de nuevo hay "muchas espadas también" en otros cuadros (1094); en p. 1083 el narrador Deza piensa ante un escaparate en comprarse una espada, explícitamente para disponer, como Tupra, de la capacidad de infundir miedo (1083), y en 1105 ss. se plantea la posibilidad igualmente de pedir y recibir una espada o estoque en préstamo para proceder, de nuevo como en el caso de Tupra, a un escarmiento, un arma que luego será sustituida por la más cómoda pistola. En 1155 s. y sólo de pasada se mencionan "las espadas" y luego de nuevo "una espada" en la escena de la violencia ejercida contra Custardoy en Madrid. En 1159 una vez más y en ese mismo contexto se cita "una espada” rememorándose su empleo por parte de Tupra en boca del narrador, que amenaza al citado Custardoy, al que ya ha herido en una mano: “...Siempre estaremos a tiempo de darle a la otra, o de cortártela con una espada, tengo un amigo muy ducho al que le encanta la espada, allí en Londres". Todavía en 1168 se mencionan "espadas de cazoleta" en el catálogo de armas de la familia Deza. Y en 695 s. y 698 el narrador hace cábalas en torno a este tema obsesivo, que aún retorna en sus preguntas en 735 . Todo ello sin referirnos a alguna expresión tópica como la "espada de Damocles" en 1236. Y, desde luego, en la justificación en boca de Tupra, a la que nos referiremos luego, la espada desempeña un papel de primera magnitud. De modo que, si bien es conocida la afición de los narradores de Marías a las repeticiones y a los ecos de lo dicho previamente (véase Grohmann 2002), nuestra sospecha es que en esta novela esa densidad de alusiones internas, que se acumulan durante o después del episodio en cuestión, marca un contraste con el texto previo, lo que razonablemente puede deberse a la importancia que tiene esta arma en aquél.

En suma, la llamativa y muy particular aparición y en especial el uso que se hace de una espada en un episodio muy concreto puede ser una razón de peso para la red de menciones de esa y otras armas a lo largo de la novela, así como en particular de las referencias a la espada cuando se narra o se ha narrado ya tal episodio. Una red que se despliega como un denso juego de anacronismos en torno al particular anacronismo del empleo de una espada en él. Lo que, sumado a su inverosimilitud, lo dota de una notable importancia y se añade al lucimiento literario de su planteamiento y desarrollo.

El anacronismo, pues, está en este episodio estrechamente ligado a la inverosimilitud en el sentido que ya hemos comentado. Y no es naturalmente, repetimos, por la sola presencia de una espada por lo que empleamos este término, sino porque la situación descrita, las propias circunstancias en que se enmarca la escena, hacen sumamente improbable la aparición de esa arma y su consiguiente uso. De ahí, lógicamente, las vueltas y revueltas con que el narrador y el propio Tupra proceden para justificar, como ya adelantábamos, esa presencia y ese empleo. De ahí que, con ese trasfondo descrito, el lector, incluso un lector tan experimentado como Ródenas de Moya, pueda fácilmente dejarse persuadir 
por una hipótesis que ligue esta obra de Marías en particular y más en concreto el episodio de Tupra y su espada con un retorno alusivo, intertextual, a una obra como Don Quijote y a un pasaje como el del duelo entre el vizcaíno y el caballero de la Mancha. En cambio, por establecer una fácil comparación, la lanza con que es asesinado un personaje muy secundario en otro momento posterior del relato se explica con mucha más facilidad y es bastante más difícil que el lector tenga la misma impresión de extrañeza y de hallarse ante un anacronismo y una grave inverosimilitud. Nos referimos, por supuesto, a la muerte de un chapero con una lanza en casa del llamado Dearlove y que se nos narra indirectamente como noticia periodística (1193 ss.): esa lanza forma parte de la decoración de la vivienda, por lo que su uso no es inverosímil ni admite comparación con el de la espada de Tupra. En este caso, el supuesto anacronismo del arma empleada se explica mucho más fácilmente: el homicida posee en la vivienda en la que ocurre el suceso armas diversas y, entre ellas, lanzas que tiene "colgadas en un salón contiguo al comedor" (1194).

Pero no son estas cuestiones estrictamente las que nos han llevado al detenido examen del episodio citado y a escribir estas páginas, sino la del posible origen o fuente inspiradora de su invención. Puesto que la agregación de esas cualidades que lo hacen destacar en el conjunto del relato induce a pensar que su origen bien podría remontarse a un texto preexistente. Y, como tal, se impone la tarea del descubrimiento de ese supuesto hipotexto o fuente inspiradora con el rastreo de cualesquiera posibles pistas que se den, si es que se dan, en la novela misma apuntando a ese origen.

Pues bien, uno de los estudiosos más conocidos de Marías ha señalado que en este episodio se nos ofrece precisamente un eco de aquel del encuentro armado, en el Quijote (I, 8), entre el vizcaíno y el hidalgo manchego, los cuales, espadas en alto, deben esperar por el recurso artístico de la suspensión narrativa, supuestamente obligada al faltar la continuación de la historia, a que en el capítulo y parte siguientes (véase luego n. 20) el narrador haya logrado dar con la fuente de aquélla. Se produce así un corte, no sólo tipográfico o editorial (paratextual), sino explicitado narrativa y metaliterariamente al final del capítulo: "Pero está el daño de todo esto que en este punto y término deja pendiente el autor de esta historia esta batalla, disculpándose que no halló más escrito... Y así con esta imaginación no se desesperó de hallar el fin desta apacible historia, el cual, siéndole el cielo favorable, le halló del modo que se contará en la segunda parte".

Aunque éste no sea nuestro tema, no tiene por qué estar de más decir que hoy sabemos que la originalidad cervantina es relativa, incluso que su inspiración puede ser múltiple, puesto que todo apunta tanto a los propios libros de caballerías como a la épica renacentista, en especial al tan influyente Ariosto, y posiblemente sobre todo a Ercilla ${ }^{14}$. La suspensión explícita de la continuidad

14 Véase un breve y excelente resumen de la cuestión en Georges Güntert 1995: 271-283, donde se trata en concreto de este episodio de la novela cervantina. Y, por supuesto, la clásica 
narrativa es un recurso muy antiguo y ha sido aprovechado muy diversamente. Sin embargo, un escritor hábil y conocedor de la historia literaria puede extraer de él, como ha hecho Cervantes, alguna novedad a pesar de la larga explotación a que ha sido sometido. Y conviene señalar que dentro de la materia concreta de la estructura formal, que es un aspecto que nos interesa en especial, en ciertos libros de caballerías que han solido mencionarse como uno de los posibles modelos cervantinos falta la que Güntert llama la "función específicamente irónica" de este tipo de suspensiones, dándose sólo un "empleo retórico-persuasivo", lo que a todas luces es diferente. En el caso de Marías también con toda evidencia aquella función irónica y toda la divertida parafernalia que acompañan la suspensión, tan detectables en Cervantes, creemos que faltan absolutamente. En suma, y anticipándonos a nuestro análisis, en Cervantes, sean cuales sean el modelo o los modelos, podemos hablar de una suspensión expresiva en alto grado, al haber utilizado el alcalaíno como el principal de sus recursos la parodia, y no sólo de tópicos caballerescos como el del libro o legajo encontrado, lo que tampoco puede decirse en modo alguno en el caso de Marías.

El estudioso al que nos referimos, el profesor Domingo Ródenas de Moya, en un capítulo que se lee en un libro colectivo, ha escrito unas frases que, referidas a Tu rostro mañana, conviene citar por entero porque constituyen el punto de partida y principal estímulo del tema que debatimos, al tiempo que la expresión concreta de su pretendida solución al problema planteado: "La elipsis y la suspensión, argucias utilizadas genialmente por Cervantes en el Quijote (y luego por sus discípulos ingleses, empezando y de qué modo por Laurence Sterne), se convierten para Marías en artificios compositivos que tan pronto pueden deslumbrar como aburrir al lector atrofiado por la cultura del zapeo, el spot y el sampling. (Aunque también rezongará el lector que pide al relato que pasen cosas). Así ocurre con el homenaje a la suspensión, en el Quijote I, 8, de la batalla entre don Quijote y el vizcaíno, un homenaje que Marías estira hasta el límite en Baile y sueño, donde Tupra como un aberrante pero despiadado don Quijote mantiene en alto su temible espada sobre el pobre diablo de De la Garza..." (2009: 68).

Ródenas de Moya no va más allá en su referencia al episodio cervantino. Y la cita del episodio de Marías no es sino un ejemplo, pero aducido sin la menor vacilación, con el uso del término homenaje, lo que refuerza la supuesta vinculación de ambos textos, sin que falte una comparación complementaria entre las figuras de don Quijote y Tupra. Por tanto, como nuestro examen de la propuesta de Ródenas es detallado y con un horizonte aun más dilatado, podría echársenos en cara una conducta desproporcionada, al responder a una breve incursión en las hipotéticas relaciones entre las dos obras con un prolijo debate.

monografía de Maxime Chevalier de 1966, sobre todo 452 ss. Los dos autores de este artículo hemos replanteado el tema en otro de próxima aparición con el título "Sobre el debatido origen del episodio del vizcaíno en el Quijote”. 
En todo caso, si la dependencia que Ródenas cree ver del episodio cuyo centro es la actuación de Tupra respecto al del vizcaíno se hubiese expresado como un hecho simplemente posible pero sujeto a debate, es decir, como una mera opinión expuesta de modo pasajero y por ello sin la perentoria necesidad de unas justificaciones, es probable que no nos hubiésemos lanzado a pensar más en la cuestión y menos a una discusión a fondo del tema. Pero el profesor Ródenas ha acompañado su afirmación de unas bases más amplias, al contemplar esta supuesta relación entre dos episodios en el contexto de una dependencia a mayor escala de Marías respecto a Cervantes (y Sterne) y sobre todo en el ámbito de la suspensión narrativa. Lo que nos autoriza, creemos, a someter su afirmación, pues de esto se trata y no de una mera sugerencia o fugaz opinión, a un análisis concienzudo, sin por ello tener que entrar en la materia de la dependencia a un nivel superior y mucho más general de la citada novela de Marías respecto a Cervantes. Aunque debamos añadir, para justificar el interés del tema, que, tal como se nos narra ese episodio, éste, según su extensión y pretensiones, parece haber sido concebido, si no como central en la novela, como muy relevante y, nos atrevemos a imaginar, también como uno de los más brillantes, de modo que la pretendida influencia cervantina cobraría, de ser cierta, una extrema importancia para la interpretación de la obra. En todo caso, la comparación entre Tupra y don Quijote sólo será tocada tangencialmente, y esto por dos razones que nos parecen convincentes: la primera es que Ródenas la ha expresado con un "como", sin sostener de modo explícito la idea de una inspiración, lo que no justificaría que la interpretásemos, abusivamente, como una afirmación en ese sentido preciso. La segunda es que la personalidad de Tupra tiene un gran peso en toda la novela y el análisis de esa comparación forzosamente desbordaría nuestros propósitos, que son mucho más modestos. Lo que no quita para que podamos expresar, también de pasada, nuestras dudas acerca de la entidad de la comparación misma. Sin que haga falta decir, como veremos de inmediato, que la comparación con don Quijote se le ha ocurrido, además de a Ródenas, a algún otro estudioso, si bien no precisamente pensando en Tupra, lo que complicaría aun más nuestra tarea.

De hecho, no puede sorprendernos que un lector crea hallar reminiscencias cervantinas, o de Sterne, en este relato. Respecto a las primeras, María Aranda, en un artículo que, en nuestra opinión, mezcla desafortunadamente los datos objetivos con divagaciones, estudió no hace muchos años, pero no tantos como para poder abarcar la novela completa, los ecos del Siglo de Oro y en particular de Cervantes (2005). La autora comienza por subrayar, sin embargo, que son "escasas", aunque "muy cuidadas" (189), las referencias de ese tipo en la parte titulada Fiebre y lanza, la única examinada. El Siglo de Oro recibe ciertas calificaciones, pero lo que lógicamente más nos importa son las menciones de Cervantes y de don Quijote, desde luego muy pocas y ajenas, todas, a nuestro tema. No obstante, nos gustaría salir al paso de algunas de las que hemos 
llamado divagaciones, en particular las que trazan una especie de paralelo entre la figura de Peter Wheeler y el hidalgo de la Mancha. Así, leemos (192): "Los extensos parlamentos del catedrático dirigidos a su discípulo producen un leve vértigo, como si en el arte del diálogo se transparentara el de la Triste Figura y su criado", una afirmación seguida de reflexiones sobre el propio Wheeler como "soldado-escritor" y el fácil pero nada convincente parangón con Cervantes o el de la comparación de las peroratas de aquél con el discurso quijotesco sobre las armas y las letras (ibid.). Uno de los textos cervantinos a los que con más apego acude el narrador ("adiós, gracias, adiós, donaires...") ni siquiera pertenece a Don Quijote sino al Persiles y Sigismunda, y las varias menciones de Alcalá de Henares como lugar de nacimiento de su autor (194) no pueden significar nada para la materia que nos ocupa.

Otro estudioso ha dejado constancia y con cierto tono de autoridad de ciertas reminiscencias o influencia en general que forman parte de un hecho amplio y constatable. Nos referimos en concreto a César Pérez Gracia, que ha escrito: "Tu rostro mañana, la dilatada novela de Marías, viene a ser una secuela de oro de esa escuela de Cervantes-Sterne. Los tonos de ambos -Sterne y Marías- nada tienen que ver, pero la técnica es similar" (2005: 77). Recordemos que Marías tradujo la célebre novela de Sterne Tristram Shandy y que muchos consideran que su amor a las digresiones, además de un rasgo de estilo propio, es una forma de arrimarse a este autor consagrado. Y Pérez Gracia dice también: "Escribir buena novela es parar el tiempo. Detener a los personajes en un escalón y hacerles hablar por los codos de forma fascinante. Esto es lo que hizo Sterne en su Shandy y lo que ha hecho Marías -sin el menor aspaviento pero de forma prodigiosa- en su monumental novela Tu rostro mañana. Una novela con 1600 peldaños" (79)15. Y sigue: En Sterne está "la consagración del capricho digresivo" (81) y "Marías ha aprendido de Sterne a ralentizar el tiempo novelesco. La digresión como duración alternativa de la narración" (82). Desde luego, la entidad reciamente digresiva de la escritura de Marías está exacerbada en esta novela, como se ha comentado más de una vez. Así lo ha hecho, por ejemplo, el citado Ródenas de Moya, que en el libro y en el mismo lugar mencionados escribe: "Las inmoderadas digresiones, alimentadas por graves asuntos o por bagatelas (que también las hay), provocan continuamente la paciencia del lector más roncero, el que espera ser tironeado todo el tiempo por la sucesión de acontecimientos de la trama, y le obligan a trasladarse de la histoire al discours, del suceso a la palabra que va tejiendo el texto y que se obstina en ser cavilosa e inquisitiva”. Pero una cuestión es la de la continuidad en un nivel técnico y general como éste o la práctica compositiva de rasgos como la digresión o la suspensión en el hilo del

${ }^{15}$ Aclaremos para el lector inadvertido: la referencia a los "peldaños" tiene que ver con una muy celebrada conversación en una escalera de dos personajes de la novela de Sterne. Y en el relato de Marías se da un eco bastante visible en otra conversación, entre el narrador y el personaje Wheeler, que tiene lugar en otra escalera (86 ss.). 
relato y otra muy distinta la imitación de episodios particulares. Y desde luego referencias tan amplias como las señaladas, cuando hablamos de esta novela, al influjo en gran escala de Cervantes o de Sterne deben especificarse, lo que no se ha hecho en detalle todavía, excepto en algún que otro caso aislado, como ocurre con la ya aducida opinión del profesor Ródenas acerca del episodio de la espada.

Lo escrito por este estudioso respecto a las "inmoderadas digresiones", sin relación directa con el tema de la fuente del episodio, será útil para nosotros sin embargo cuando nos refiramos a la morosidad narrativa como un elemento relevante que debe ser tenido en cuenta. Pero, respecto a la vinculación establecida, comenzaremos por decir que no tenemos certeza alguna de que estemos ante una imitación, un eco o menos aun un homenaje literario al citado episodio de Cervantes, como tampoco, dicho sea de paso, ante un remedo de Sterne ${ }^{16}$. Y ni siquiera, en fin, de que nos hallemos ante una simple alusión al pasaje cervantino. $Y$ es que, en cuanto a Cervantes, las diferencias son muchas y las hipotéticas semejanzas nulas, excepto en el simple hecho de que se blande una espada, que, además, en el Quijote son dos, puesto que se trata de un duelo entre dos antagonistas, mientras que en Tu rostro mañana asistimos a una escena de violencia, o, más bien, de amago de violencia, ejercido por un individuo (Tupra) contra otro (De la Garza) inerme y aterrorizado. Ya la actitud misma de Tupra nos alejaría de la supuesta emulación. Y desde luego que este personaje tenga alguna inspiración en la figura de don Quijote y, sobre todo, que esta supuesta ascendencia literaria justifique otra también supuesta inspiración del episodio que estudiamos en el citado capítulo de la novela cervantina ya hemos dicho que nos parece fuera de lugar ${ }^{17}$. No hace falta llenar aquí muchas líneas para recordar cómo el tal Tupra es una criatura de ficción absolutamente alejada en su conducta de la de don Quijote. En cuanto a la que podría haber sido una emulación más alambicada, de Cervantes a través de Sterne, nos parece una vía todavía más claramente cegada. Salvo la ya referida charla en la escalera entre el narrador y Wheeler, que puede ser, como hemos apuntado, un eco superficial de una celebrada conversación en el texto de Sterne, no encontramos en Tu rostro mañana ninguna otra rememoración de este autor que sea evidente, y menos en

16 Ródenas no menciona la imitación cervantina por parte de Sterne, evidente y literariamente eficaz por su carácter paródico, pero de la que muy difícilmente podrían rastrearse huellas en el texto de Marías. No obstante, éste ha procedido a homenajear a Sterne en otro momento de la novela, donde, entre una serie de viajes, se nos cuenta una visita a su casa museo en Coxwold, en Yorkshire (956 s.).

${ }^{17}$ No hemos encontrado en nuestra consulta bibliográfica ninguna referencia al que podría haber sido un paralelismo entre personajes y en concreto con Tupra como uno de ellos: nos referimos al posible, pero para nosotros improbable, eco en la figura de Tupra de un diestro espadachín como es el licenciado que en I, 19 no sólo hace una exhibición con el arma sino que "canta las excelencias de la espada", lo que en cierto modo también hace Tupra en el relato de Marías. 
relación con nuestro tema, pues la mencionada visita a la casa-museo del escritor inglés es totalmente ajena al episodio de Tupra y su espada.

Es irrelevante, desde luego, y no puede usarse como argumento para la supuesta influencia de Cervantes, que el nombre de éste y el del título del Quijote aparezcan, según hemos visto, en la novela de Marías, pero nunca en relación con el episodio cuya inspiración indagamos. Incluso cuando se cita a don Quijote dentro de éste, como ocurre en p. 504, o ya en el marco de sus secuelas (717), como todavía después en $1132^{18}$, no se trata en ningún caso de un recuerdo ligado al encuentro del hidalgo con el vizcaíno ni, por supuesto, como modelo del texto estudiado.

Ignoramos, por otra parte, si en alguna de sus innumerables entrevistas publicadas el autor, Marías, se ha referido a este episodio de su novela en el sentido de que en él haya podido o intentado proceder a imitar a Cervantes. Al menos el profesor Ródenas de Moya, reconocido como un experto en la obra del prosista, no hace en su texto la menor mención de esa posibilidad. Como tampoco se refiere a que algún otro estudioso o crítico se le haya adelantado en la expresión de esta idea ${ }^{19}$. Y no hemos encontrado alusión alguna posterior a la propuesta del profesor Ródenas. Sin que haga falta decir que no podemos entrar en el subconsciente del escritor Marías para indagar si en él pesó en algún momento el episodio quijotesco al redactar el suyo. No obstante, incluso aunque el propio autor o cualquier estudioso hubiesen hablado o escrito sobre ello, este hecho no sería motivo suficiente para retirar nuestras profundas reservas: simplemente rectificaríamos nuestro enunciado en el sentido de que quien se equivoca no es el profesor Ródenas sino, antes que él, algún otro lector de la novela o el novelista mismo, al haber confiado éste en el éxito de su escritura como inspirada en Cervantes, cuando hay suficientes argumentos en contra de aceptar, si se nos permite expresarlo así, algún parentesco entre un texto y otro. En ese caso, improbable, la concepción del moderno episodio padecería la grave tacha de haber pretendido estar inspirado en otro episodio novelesco, el de Cervantes, sin haber logrado hacer una imitación lo suficientemente convincente o practicar alguna alusión interpretable de modo que pueda ser detectada por los lectores. Y debemos añadir que, tal como Ródenas plantea el tema, tal inspiración sería indudablemente intencionada, un acto de intertextualidad evidente, aunque quedaría por ver si productiva, es decir, verdaderamente significativa en el texto de Marías. Lo que, además, debería llevarnos a un largo debate acerca de si en las relaciones intertextuales puede bastar con las intenciones (o supuestas intenciones) del emulador, sin que deban existir elementos textuales objetivos sobre los que basar el análisis. Nuestra posición en este caso es inapelable: nos

${ }^{18}$ Con una muy particularizada referencia a la pasión del caballero por Dulcinea.

19 Una reseña periodística de Juan Antonio Masoliver Ródenas (2004), a pesar de su prometedor título y de referirse a uno de los volúmenes de Tu rostro mañana, es totalmente ajena a nuestro tema. 
negaríamos a entrar en una discusión acerca de meras e imaginadas intenciones y sin la existencia de esos elementos textuales objetivos a los que recurrir.

Según recordamos, el narrador cervantino no quiere arrogarse esta ocurrencia narrativa: la atribuye al accidente de la falta documental que le fuerza a esperar hasta que aparecen en el Alcaná de Toledo ciertos "cartapacios y papeles viejos" donde se lee la continuación. Nos deja en suspenso y procede ahí, presuntamente forzado por el fallo de sus fuentes, a un cambio de capítulo e incluso de parte ${ }^{20}$, dando pie a tantos y sabrosos juegos presentes en Sterne entre la narración y, precisamente, el reparto del texto en capítulos. En el Quijote tenemos, pues, tres elementos: un relato, que es suspendido muy novedosamente incluso en la actitud física de sus personajes, el salto de un capítulo a otro (y de una parte a otra originalmente), lo que refuerza en el plano formal esa suspensión narrativa, y la presencia subsiguiente de una digresión, como explicitación motivada de esa suspensión narrativa. En Sterne se repite la suspensión, con el nuevo detalle del tiempo que se supone realmente transcurrido (de hora y media de reloj según su narrador), en tanto que la foto fija con el caballero andante y su antagonista el vizcaíno con las espadas pasa a ser la de Walter tumbado en su cama y tocando el orinal que está bajo ella y el tío Toby sentado a su cabecera en una butaca (III 29), una escena igualmente estática a la que sigue un buen número de páginas hasta el retorno a esa misma situación (IV 2).

Ahora bien, de todo esto no encontramos reminiscencia alguna en el episodio de Marías. Éste no ha buscado la perspectiva humorística y tampoco la quiebra de una acción unida a una presentación editorial, y si hay, más que suspensión, lentitud narrativa, estamos simplemente ante su modo habitual de proceder. En cambio, en su relato, en el que, como tantas veces en esta novela, las referencias a la violencia son uno de los fundamentos textuales, tenemos un tipo de episodio que se pretende dramático, incluso angustioso. Y mucho dudamos de que algún lector pueda ver en él el sentido del humor que ciertos críticos creen tan relevante en la escritura de Marías. En cuanto al recurso de la suspensión del relato, en una novela que está plagada de aplazamientos motivados sobre todo por el abundante entrelazado de los episodios y las muchas y extensas digresiones, estamos en todo caso ante un hecho narrativo y formal muy general. En tanto que en Cervantes la quiebra narrativa destaca justamente por ser una grave anomalía.

Desde luego, insistimos, no existe una suspensión comparable a la cervantina. La primera vez que Tupra amaga con su golpe la espada se detiene en seco en el aire "a un centímetro o dos de la nuca" de De la Garza, de modo que es sólo en la imaginación del narrador donde tiene lugar el descabezamiento (630); la segunda vez ("en seguida la alzó de nuevo... Cuando detuvo la espada y

${ }^{20}$ Recordemos que en la primera edición del Quijote (1605) el volumen se dividía en cuatro partes y que justamente el episodio del vizcaíno, dividido narrativamente, está a caballo entre dos de ellas. Algunas ediciones modernas o indican esto, por ejemplo, sólo en notas, o lo soslayan. 
volvió a levantarla y así volvió a parecer que iba a matarlo... La espada había descendido brutalmente pero se había parado antes de alcanzar su cuello y ahora volvía a su posición en alto...": 634 s.) tampoco hay sino el amago detenido y no una suspensión narrativa semejante. Se insiste en ello: "Tupra sacudió la espada con tanto brío que sonó como un latigazo en el aire, y esta segunda vez hizo lo mismo con su gran dominio, la detuvo en seco sin que la hoja llegara a entrar en contacto con cuerpo alguno... Entonces mantuvo el filo un momento muy cerca del cogote encogido..." (636). Luego Tupra "levantó la lansquenete, la alejó de la nuca rozada... Entonces Tupra bajó la mano izquierda, cogió la redecilla... Y después bajó la espada" (639), por tercera vez, pero en esta ocasión, con el final de un capítulo (no numerado), para seguir inmediatamente con el relato: "Le cortó la redecilla de un tajo...", y ya cesar definitivamente en su amenaza (641 s.).

La única interrupción formal se da, pues, en este tercer y último amago, sin que se produzca una real suspensión en el nivel de la acción y menos un excurso justificador de ésta, es decir, los que son los dos ingredientes más llamativos del relato cervantino. En Marías el paso de un capítulo a otro, incluso si, como mera hipótesis, estuviese inspirado en el alto narrativo del autor de Alcalá, no tiene aquí entidad alguna. Y, en sentido amplio, es la mencionada morosidad del relato, tan típica de Marías y ya señalada por el profesor Ródenas, la que refuerza las propias acciones, una y otra vez interrumpidas, de Tupra. Una morosidad que ofrece dos niveles: la lentitud estilística, de la propia narración, y las imbricaciones, tan usuales en la conducta de Marías como novelista, de los pensamientos, aprensiones e incluso visiones del narrador. Dos aspectos ajenos totalmente al relato de Cervantes.

Momentáneamente se introduce en el episodio una (bastante vaga por cierto) perspectiva literaria que, si hablamos de influencias, podría también ser engañosa respecto a nuestro debate. El personaje De la Garza, según lo imaginado por el narrador, exclamaría ante el primer amago y refiriéndose al propio narrador como testigo del hecho: “...Ni siquiera intentó pararle el brazo, bueno, los dos, porque el muy cabrón agarró la tizona con ambas manos para atizarme con toda su fuerza, toma literatura medieval y universal...” (631). O, de otro modo, en la única referencia literaria que leemos, la expresión es confusa y demasiado general para que podamos ir más allá de una visión de una escena del medievo en la que el empleo del término "tizona" puede considerarse especialmente significativo.

En cuanto a la improbabilidad del episodio, ya señalada, es indiscutible. No sólo se trata de un uso, el de la espada, anacrónico, sino de un empleo extraño por fuera de lugar, hasta el punto de que en el relato, como ya adelantábamos, se vuelve luego una y otra vez sobre la necesidad de justificarlo. Una justificación que, literariamente, estaría, según la propuesta citada, en el supuesto modelo cervantino. Como tampoco hace falta aclarar que la suspensión narrativa en 
Don Quijote está al servicio de un recurso específico en el nivel de la trama: se sobreentiende que los dos personajes del duelo continúan su lucha a muerte y que su inactividad corresponde exclusivamente al modo en que se nos narra el episodio. En cambio, en Marías la espada no sólo se alza para golpear sino que de hecho desciende, y más de una vez, sobre la víctima, para quedar tan cerca de su cuello como para que la amenaza sea totalmente creíble. Sólo que la espada no golpea ni estaba previsto que lo hiciera. Forma parte, como literal "sablazo", de las medidas "escarmentadoras" de las que se ha hablado anticipadamente (503).

Y también se puede hacer notar, además de la tendencia arcaizante y la inverosimilitud, que aquí van de la mano, la desproporción entre el suceso que da lugar a la actuación con la espada y el acto punitivo de Tupra, desproporción que el narrador reconoce muy explícitamente: "Pero en este caso de qué se había vengado, era un exagerado, un drástico: de una nimiedad, de una estupidez"(767). En tanto que en el episodio quijotesco la actuación del hidalgo no responde a venganza alguna, sino al doble tópico típicamente caballeresco de enderezar un entuerto y confirmar la dignidad de su pasión por Dulcinea.

Creemos, pues, que se equivoca el profesor Ródenas de Moya. Como también creemos que tampoco anda muy acertado, en un nivel más amplio, Pérez Gracia al creer ver en esta novela una densidad de influencias de Sterne y de Cervantes. Él mismo parece limitarse a un hecho muy general: la suspensión del tiempo, que, sin embargo, no es invocable como un principio básico en el Quijote. Pues no operan estrictamente en este sentido los relatos intercalados, y el planteamiento del episodio de las espaldas en alto es un hecho aislado. Y, en todo caso, quienes insisten en el influjo de Sterne suelen referirse también precisamente a la tendencia a la suspensión temporal, pero como hecho general y no específico de aquel episodio de Marías: es lo que sucede con Pérez Gracia y su citado tema de los "peldaños". Sin que haga falta repetir que las muy extensas digresiones no son, en Tu rostro mañana, sino la culminación de la que ha sido una tendencia habitual ya en sus anteriores novelas.

Vamos a examinar ahora la cuestión aun más en detalle. $\mathrm{Y}$ trataremos también de encontrar una respuesta al problema del posible origen de este episodio, diferente por supuesto de la expuesta por Ródenas de Moya. Pero antes deseamos salir al paso de otra hipótesis, que no hemos visto formulada, si bien sería fácil que se expusiera en la búsqueda de un origen para el uso de la espada por parte de Tupra. Se trataría en este caso de un origen "lingüístico", si se nos permite decirlo así, y que, en teoría, podría haber estado en la mente de Marías al redactar este texto. Sin embargo, no lo creemos probable, puesto que Marías en este caso habría cometido un grave desliz. Y es que en castellano existe la expresión "espada ropera", que podría inducir a la falsa interpretación de que se trataría de un arma, como la de Tupra, llevada a escondidas. La expresión parece ser de origen castellano y ha dado equivalentes en otras lenguas ("rapière" 
en francés, "rapier" en inglés, "spada a striscia" en italiano...). Se impuso en el Renacimiento como parte de la indumentaria civil y como arma de defensa personal, pero, en nuestra opinión, todo parecido con el arma y el uso y sobre todo el disimulo inherentes a la persona y actuación de Tupra es más que remoto. De vuelta al principio de nuestra discusión, es obligado comentar también que el que don Quijote y el vizcaíno manejen espadas es un hecho natural en su contexto. También es un hecho natural que el padre de Tristram tenga en su dormitorio un orinal; lo que ya no es natural, sino muy inverosímil, es que Tupra se pasee con una espada por una discoteca, aunque sea enfundada en una vaina disimulada en su abrigo. El narrador mismo expresa su extrañeza: “...Sin que uno haya visto aparecer el arma ni sepa de dónde ha salido... el arma blanca más innecesaria o más reñida con estos tiempos, más aún que una flecha y más que una lanza, un anacronismo..., una extravagancia, una incongruencia tan extrema..." (627 s.). Y más adelante el mismo narrador le habla a Tupra de su "original" posesión de armas (725). Pero esa extrañeza se refiere a la rareza actual de la propia arma mucho más que a la incongruencia de la situación. Si Tupra, en fin, es hombre de recursos, ésta no es una justificación suficiente para explicar la aparición de un arma tan desusada y en un lugar tan inadecuado.

Mucho nos tememos que, en parte y ya en una primera impresión, ha sido simplemente esa su fuerte tendencia a los arcaísmos, ya aludida, la que puede haber llevado a Marías a convertir esta inverosímil espada en el centro del episodio. Y un indicio de ello, de que su empleo es, justamente, inverosímil y por ello nada fácil de justificar, es que tanto el narrador como el personaje Tupra se esfuerzan en buscar, como dijimos, variadas explicaciones. En cuanto a que Marías como escritor dirige habitualmente su mirada al pasado, con cierto desdén hacia el presente, es un hecho demasiado conocido para necesitar pruebas. Bástenos recoger una frase de otro de sus estudiosos, Jordi Gracia, que, al escribir en concreto sobre Tu rostro mañana, dice lo siguiente: "Como si todo siguiese igual que en los tiempos en los que Shakespeare -trama textual de toda la novela y hasta de sus subtítulos- urdió sus tragedias...” (2009: 64)21.

Desde luego, la aparición de la espada en escena no se atribuye jamás a una improvisación, a un azar o, en todo caso, ni siquiera a un contexto o escenario propicio, como sí ocurre en el ya mencionado episodio del lanzazo con el que otro personaje, Dearlove, asesina a un supuesto compañero sexual y en el cual la lanza tiene una fácil justificación. El escenario y las circunstancias del episodio protagonizado por Tupra, en cambio, son lo menos apropiado imaginable para la aparición y uso de esta arma: una sala de fiestas atestada de clientes. Tupra, se

21 Sobre el narrador de esta misma novela ha escrito Sebastiaan Faber: "Es verdad que el narrador tiene una tendencia natural a idealizar el pasado; nostálgico que es, son innumerables los momentos en que se queja de la decadencia cultural, moral, lingüística y estética de la época presente. Más allá de esta inclinación más bien neurótica hacia las posturas reaccionarias...” (2009: 220). 
nos dice, "lo había previsto todo" (691), pero sólo como una referencia al plan improvisado del castigo, no al hecho de haber ido a la discoteca ya provisto de una espada. Aunque el modo en que se transporta ésta, guardada en una vaina disimulada en el abrigo, induce a pensar que el personaje está acostumbrado a hacerlo ${ }^{22}$ y que puede haberlo hecho en ciertas ocasiones en las que se supusiese que el arma podía ser utilizada, no es éste el caso en el episodio que estudiamos. Nada hacía prever que en esa noche y en esa discoteca pudiese haber la necesidad de ese empleo amenazador. Ni se nos dice que Tupra portase sistemáticamente su oculta espada en cada salida nocturna semejante, aunque sí, en efecto, se alude vagamente a un cierto hábito. Nadie podía prever que en esa situación apareciese y actuase del modo en que actúa el personaje De la Garza, que con su conducta desencadena el castigo. El narrador, que, según vimos, califica ese transporte como una "original posesión de armas" (725) y que previamente ignoraba que Tupra pudiese portar un objeto semejante a pesar de haber participado junto a aquel en otras actividades sociales parecidas, lógicamente queda muy intrigado por el hecho y cavila sobre esa presencia inimaginable del arma en tal situación: "Tampoco era descartable que la espada no la hubiera traído [Tupra] desde el principio consigo, que no lo acompañara siempre, que se la hubieran proporcionado en el guardarropa junto con la prenda, al pedirla; que a una señal suya se la hubieran metido en el largo bolsillo-funda, que la tuviera en depósito en aquel local, por así decir, y se la pasaran cuando le hiciera falta..." (695 s.). Una suposición que es tan disparatada o inverosímil como la explicación real que luego se nos dará: que Tupra la ha traído consigo, tal como después se la llevará, y que en él es precisamente una costumbre el hacerlo. $Y$ no hace falta decir que, cuando no hubiese necesidad de llevar un abrigo, Tupra no podría apelar a espada alguna en una situación semejante, lo que acrecienta la improbabilidad del recurso a esta arma concreta. $\mathrm{Y}$ el propio narrador se interroga igualmente por el sentido no ya de portarla, sino de hacerlo para un uso sólo como amenaza, lo que acrecienta también la extrañeza del hecho: "Quizá hay que preguntarse por qué la sacó, antes que nada. Era aparatosa e innecesaria, y al final no la utilizó siquiera, sólo para... darle un susto de muerte a la víctima...” (698), lo que, añadamos, no es lo que ocurre en el caso del episodio quijotesco, en el que se busca herir o matar con las espadas. Y todavía más tarde se insiste en este punto: al narrador, cuando vuelve a cavilar sobre el tema, le parece "tan improbable, tan anacrónico, tan inverosímil..."(840).

El transporte y uso de la espada requieren sin duda una justificación. Y el narrador no sólo muestra su propia extrañeza sino que hace en varios momentos sus cábalas sobre el tema, así como exterioriza sus quejas por el penoso espectáculo del duro castigo a De la Garza. Tupra aparece como un individuo frío y endurecido, profesionalmente entregado a una tarea igualmente tan poco verosímil como la de dirigir una agencia en la que se estudian, sobre la base del

${ }^{22}$ Cf. lo que leemos en p. 695. 
examen de fisonomías, gestos y palabras, los entresijos de las conductas no ya presentes o pasadas sino futuras, y es lógico que sus propios actos tengan una explicación esencialmente sicológica pero no siempre fácil. La espada forma parte de un juego de terribles amenazas (cf. 698), por lo que el fin de su empleo no es el sangriento cumplimiento de esas amenazas sino la mera exhibición amenazadora.

El propio Tupra alega un ejemplo inspirador y ligado al fin sicológico que él defiende para el uso de la espada: el terror infundido por los hermanos Kray (Ronnie y Reggie, es decir, Ronald y Reginald) en los años cincuenta y sesenta del siglo pasado en Londres. Como ocurre tantas veces en esta novela, se apela a hechos y personajes históricos de las décadas previas. Y, efectivamente, los "Kray twins" gozaron de cierta celebridad local tanto por sus actividades sociales como por sus graves delitos, de modo que informarse sobre ellos no era difícil. Es más, en 1990 se estrenó una película con su nombre. Para el lector español, a diferencia del británico, son figuras hoy desconocidas, por lo que en el texto de Marías se nos ofrecen diversos datos. Según Tupra, "fueron de los más violentos y temidos, coléricos, con escaso control de su crueldad, algo sádicos, y al principio de su carrera utilizaron espadas" (719). Y añade: "Claro que ellos lo hicieron por necesidad, no tenían dinero para armas más caras, en sus primeros escarmientos e intimidaciones. Causaban terror, con sus sables, a sus víctimas las dejaban marcadas..." (ibid.). El narrador, en su búsqueda de una justificación razonable del uso de esta clase de armas en nuestro tiempo, insiste en el hecho: "Me ibas a dar una explicación -le dije-. De lo de la maldita espada. Los Kray y todo eso. ¿Qué es lo que aprendiste tan importante, a ser como el Zorro? ¿D’Artagnan, Gladiator, Conan el Bárbaro...?”, es decir, las figuras tópicas de aventuras tanto del pasado como del presente bien conocidas, sin que entre ellas, anotémoslo, se mencione a don Quijote. La explicación es elemental: "Es el miedo, Jack. El miedo. Una vez te dije que es la mayor fuerza que existe si uno logra acomodarse a él, instalarse, convivir con él...”, en palabras nuevamente de Tupra $(729)^{23}$. Y, en efecto, en el episodio se pretende infundir miedo posiblemente no sólo a la víctima, sino al testigo, el narrador, bajo cuyo punto de vista transcurre la escena. Pero, aun más, Tupra explica por qué precisamente ese empleo de un arma anacrónica: "Así, el miedo que uno mete o infunde no debe ser conocido, ni casi ser imaginable. Si es un miedo convencional, previsible, o cómo decirlo, trillado, el que lo padece será capaz de entenderlo, de ganar tiempo y con él costumbre, y quizás después de acometerlo". Todavía un poco más adelante Tupra insiste: "Si yo le saco a un individuo una pistola o una navaja, es seguro que se asustará, pero será un susto convencional, o trillado... En cambio, una espada... Ríete ahora, búrlate por su extravagancia, por su anacronismo, hasta por su herrumbre. Tú no viste tu cara cuando la descubriste en mis manos. Viste la del macaco, con eso debería bastarte..." (732 y 734). Y el narrador, con la insistencia repetitiva

${ }^{23}$ Cf de nuevo pp. 732 ss. 
tan típica del estilo de Marías, incide en el mismo tema: "De dónde ha salido, un filo primitivo, un mango medieval, un puño homérico, una punta arcaica, el arma blanca más innecesaria y más reñida con estos tiempos, más aún que una flecha y más que una lanza, un anacronismo, una gratuidad, una extravagancia, una incongruencia tan extrema que provoca pánico sólo verla, no ya miedo cerval sino atávico..." (735). Un tema, el del miedo infundido por un arma semejante, que vuelve a tocarse más adelante (743), de acuerdo con el método de la insistencia argumentativa también muy típico de Marías. Estamos, pues, ante una prolija explicación, pero que resulta convincente y vuelve inútil cualquier intento de hallar otra.

$\mathrm{O}$, de otro modo, el miedo adquiere una calidad diferente, más profunda, si está fundado o apoyado en la propia inverosimilitud, en el carácter intensamente sorprendente de la situación creada, en este caso no ya sólo por la amenaza y la acción, sino por lo inaudito del arma que representa la propia amenaza. De ahí que el arma no necesite herir para asustar, basta con la exhibición, la intimidación, para crear el terror, para dar una lección que se entiende como duradera, incluso definitiva. Y así la inverosimilitud del episodio, en la que hemos insistido, cobra un sentido propio, con una cualidad entendida como necesaria para el efecto deseado. Y a la vez, por retomar otro de los aspectos de este estudio, el arma como objeto, como parte de las circunstancias del personaje Tupra y de su compleja proyección sicológica en el sentido en que nos hablaba de los objetos novelísticos de Marías la profesora Pittarello, contribuyen a dibujar a este tan poco quijotesco por tortuoso y un tanto siniestro personaje.

$\mathrm{Si}$ nos replanteamos, pues, la cuestión de dónde parece haberse inspirado Marías para esta escena y, sobre todo, para el uso de esta arma tan anacrónica en el ámbito actual de las armas eficaces, la hipótesis que juzgamos razonable es que, exactamente igual que lo expresa su personaje Tupra, Marías se ha inspirado en las noticias sobre los "Kray twins", ya sea a través de la citada película, lo que es también razonable no sólo porque Marías es un confesado amante del cine, sino porque la película se nombra en el texto por boca del propio Tupra, ya sea, menos necesariamente o de modo complementario, por la lectura de las informaciones periodísticas sobre esos hampones gemelos y con ribetes de pintorescos criminales.

En el relato y en un diálogo entre Tupra y el narrador $(742 \text { s. })^{24}$ se replantea el tema de la justificación del arma o, si se prefiere, del origen de la ocurrencia de portarla y usarla. Se alude ahí irónicamente a los estudios de Tupra (Historia Medieval) y a que ese uso anacrónico pueda deberse a una especie de "añoranza" de sus tiempos de estudiante, a lo que el propio Tupra sólo responde de un modo ambiguo, sin una respuesta que pueda tomarse como un sí y sin aceptar claramente que esta explicación sea válida o pueda sustituir a la otra, es decir, a la imitación de los "Kray twins". Una intención justificadora que es paralela

${ }^{24}$ Cf. luego de nuevo p. 773. 
en cierto modo al esfuerzo que se percibe por dotar de cierta verosimilitud al hábito de portar una espada ${ }^{25}$ : ésta, contra las suposiciones del narrador, estaría habitualmente guardada en el maletero del coche de Tupra y de allí saldría, oculta en su abrigo, en las ocasiones en que fuese preciso su uso.

La solución al problema que planteábamos al comienzo no ha de buscarse, pues, en la influencia de un texto literario naturalmente previo como pudo ser el cervantino citado. Tampoco en una apelación a un pasado como puede ser el de los tiempos isabelinos, tan inspiradores para Marías, ni a un simple juego de anacronismos. Es más, la apariencia anacrónica es aquí una falacia, como luego se nos desvela. Estamos, en fin, ante una solución explicitada claramente en la propia novela y que remite a una influencia basada en noticias muy recientes, tomadas ya sea de una hemeroteca, ya sea incluso de una película. No haber percibido esto refleja, y lamentamos decirlo, una lectura apresurada y, por tanto, bastante inexplicable en quien es sin duda un especialista en la narrativa de Marías. Pero, si por parte del citado estudioso o de cualquier otro se insistiese en la validez de la propuesta que hemos discutido, creemos que el peso de la demostración debe recaer sobre ellos. No bastaría, en nuestra opinión, con argumentar que la intertextualidad no tiene por qué exteriorizarse en términos de evidencia, lo que se nos antoja, ya lo hemos dicho, un principio escasamente científico. Mientras que nuestras conclusiones se apoyan en el propio texto, mucho dudamos de que aquella propuesta tenga soporte alguno en él. Y, por apurar las posibilidades del tema, si alguien desea alegar que no tendría por qué existir incompatibilidad alguna entre esa justificación explicitada en la propia novela y otro origen intertextual de la actuación de Tupra, en principio estaríamos de acuerdo. Pero de lo segundo tendrían que dársenos argumentos basados a su vez en el texto mismo, lo que, en nuestra opinión, no ocurre. Así que, por ahora, dejamos la cuestión pendiente de que otro o el mismo estudioso desee reemprender la discusión.

\section{BIBLIOGRAFÍA}

Andres-Suárez, I., "Los cuentos de Javier Marías o las múltiples caras de la realidad”, en Javier Marias. Grand Séminaire de Neuchâtel. Coloquio Internacional Javier Marías. 10-12 de noviembre de 2003, Neuchâtel, Universidad de Neuchâtel, 2005, pp. 197-215. Aranda, M., "Narración y sombra: Función del 'Siglo de Oro' en Tu rostro mañana / I. Fiebre y lanza”, en Javier Marias. Grand Séminaire de Neuchâtel. Coloquio Internacional Javier Marías. 10-12 de noviembre de 2003, Neuchâtel, Universidad de Neuchâtel, 2005, pp. 189-195.

Chevalier, M., L'Arioste en Espagne. 1530-1650; Recherches sur l'influence du Roland furieux, Bordeaux, Université, 1966.

Echevarría, I., Trayecto. Un recorrido crítico por la reciente narrativa española, Barcelona, Debate, 2005.

25 Véanse pp. $717 \mathrm{~s}$. 
Faber, S., "La irresponsabilidad del novelista. Javier Marías, Tu rostro mañana y el debate sobre la memoria histórica", en Alli donde uno diría que ya no puede haber nada. Tu rostro mañana de Javier Marias, ed. de Alexis Grohmann y Maarten Steenmeijer, Amsterdam-New York, Rodopi, 2009, pp. 203-233.

Gracia, J., "Pensar por novelas. Tu rostro mañana de Javier Marías", en Alli donde uno diría que ya no puede haber nada. Tu rostro mañana de Javier Marías, ed. de Alexis Grohmann y Maarten Steenmeijer, Amsterdam-New York, Rodopi, 2009, pp. 61-65.

Grommann, A., Coming into one's own: The novelistic development of Javier Marias, Amsterdam, Rodopi, 2002.

-Literatura y errabundia (Javier Marias, Antonio Muñoz Molina y Rosa Montero), Amsterdam-New York, Rodopi, 2011.

Guijarro Ceballos, J., El "Quijote” cervantino y los libros de caballerías: Calas en la poética caballeresca, Alcalá de Henares, Centro de Estudios Cervantinos, 2007.

Güntert, G., “Ariosto en el «Quijote»: replanteamiento de una cuestión”, en Actas de los Congresos de la Asociación Internacional de Hispanistas, XII, Madrid, 1995, pp. 271-283.

Iriarte, A., “'Cito a menudo para mis adentros': citas y alusiones en Tu rostro mañana de Javier Marías" en Alli donde uno diría que ya no puede haber nada. Tu rostro mañana de Javier Marías, ed. de Alexis Grohmann y Maarten Steenmeijer, Amsterdam-New York, Rodopi, 2009, pp. 303-366.

Martín, R., "La destrucción de la biografía. El motivo del doble en dos cuentos de Javier Marías”, en Javier Marías. Grand Séminaire de Neuchâtel. Coloquio Internacional Javier Marias. 10-12 de noviembre de 2003, Neuchâtel, Universidad de Neuchâtel, 2005, pp. 231-241.

Maravall, J. A., Utopía y contrautopía en el Quijote, Santiago de Compostela, Editorial Pico Sacro, 1976.

Marías, J., Mañana en la batalla piensa en mí, Madrid, Alfaguara-Bolsillo, 1996.

- Cuando fui mortal, Madrid, Alfaguara, 1996.

— Corazón tan blanco, ed. de Elide Pittarello, Barcelona, Crítica, 2006.

- Mientras ellas duermen, Barcelona, Debolsillo, 2007.

- Tu rostro mañana, Madrid, Alfaguara, 2009.

Masoliver Ródenas, J. A., "La añoranza de la espada”, La Vanguardia, 24-11-2004, p. 11.

Pérez Gracia, C., "Sterne y Marías o el coloquio de los peldaños. En torno a Tu rostro mañana", en Javier Marias. Grand Séminaire de Neuchâtel. Coloquio Internacional Javier Marias. 10-12 de noviembre de 2003, Neuchâtel, Universidad de Neuchâtel, 2005, pp. 77-85.

Pittarello, E., "Haciendo tiempo con las cosas", en Javier Marías. Grand Séminaire de Neuchâtel. Coloquio Internacional Javier Marias. 10-12 de noviembre de 2003, Neuchâtel, Universidad de Neuchâtel, 2005, pp. 17-48.

Requena Hidalgo, C., "El narrador en las novelas de Javier Marías” Espéculo, 24 (2003). 
Roas, D., "Perdidos en Redonda: Javier Marías y lo fantástico", en Javier Marías. Grand Séminaire de Neuchâtel. Coloquio Internacional Javier Marías. 10-12 de noviembre de 2003, Neuchâtel, Universidad de Neuchâtel, 2005, pp. 217-230.

Ródenas De Moya, D., "Rostro completo: el tríptico de Javier Marías", en Alli donde uno diria que ya no puede haber nada. Tu rostro mañana de Javier Marias, ed. de Alexis Grohmann y Maarten Steenmeijer, Amsterdam-New York, Rodopi, 2009, pp. 67-75. Todorov, T., Introduction à la littérature fantastique, Paris, Éditions du Seuil, 1970.

Nombre del autor: Héctor Brioso Santos y Máximo Brioso Sánchez

Dirección-e: hbrioso@hotmail.com

Dirección postal: Facultad de Filosofía y Letras / Colegio San José de Caracciolos / c) Trinidad, 5 / 28801 - Alcalá de Henares, Madrid

Fecha de recepción: 03/12/2012

Fechade aceptación: 22/09/2013 
